\title{
Pengembangan instrumen penilaian bermuatan steam untuk mengukur kemampuan berpikir kreatif dan problem solving pada tema getaran dan gelombang
}

\author{
Moneyta Kurnia Pangestu, Erni Yulianti, Novida Pratiwi \\ Universitas Negeri Malang, Jl. Semarang No. 5 Malang, Jawa Timur, Indonesia \\ *Penulis korespondensi, Surel: erni.yulianti.fmipa@um.ac.id
}

Paper received: 01-04-2021; revised: 15-04-2021; accepted: 30-04-2021

\begin{abstract}
Abstrak
Kemajuan teknologi yang pesat menuntut masing-masing individu mampu menyelesaikan permasalahan yang dihadapi sehari-hari secara kreatif. Kemampuan berpikir kreatif dan problem solving merupakan suatu kemampuan yang harus dimiliki seseorang agar mampu mengikuti kemajuan teknologi. Melalui pembelajaran di kelas kemampuan berpikir kreatif dan problem solving dapat dikembangkan. Pembelajaran dengan menerapkan pendekatan STEAM akan memfasilitasi siswa mengembangkan kemampuan berpikir kreatif dan problem solving. Dibutuhkannya suatu alat ukur untuk mengetahi tingkat kemampuan berpikir kreatif dan problem solving siswa melalui suatu instrumen penilaian. Penelitian ini memiliki tujuan untuk mengembangkan assesmen kemampuan berpikir kreatif dan problem solving berpendekatan STEAM pada kategori valid daan reliabel. Penelitian ini menggunakan model 4-D terbatas pada tahap develop dikarenakan adanya keterbatasan waktu dan biaya. Produk yang dihasilkan pada kategori sangat layak dengan nilai rata-rata sebesar 94,4 persen. Uji empiris produk menunjukkan bahwa assesmen yang dikembangkan berada pada kategori valid dan reliabel.
\end{abstract}

Kata kunci: Assesmen; Berpikir Kreatif; Problem Solving; STEAM

\section{Pendahuluan}

Permasalahan yang dihadapi sehari-sehari menjadi semakin kompleks seiring dengan perkembangan teknologi yang semakin pesat sehingga setiap individu dituntut dapat menyelesaikan setiap permasalahan dengan kreatif (Mulhayatiah, et al., 2019). Melalui pendidikan, seseorang dapat mengembangkan potensinya dalam berpikir kreatif dan problem solving. Permasalahan yang dimunculkan dalam pembelajaran merupakan sarana yang tepat dalam mengembangkan potensi berpikir kreatif dan problem solving pada siswa (Rahayu Tri dan Adistana, 2018). Mata pelajaran IPA merupakan mata pelajaran yan membahas mengenai topik-topik yang berhubungan dengan gejala alam, sehingga melalui pembelajaran IPA di kelas siswa terlatih untuk untuk menerapkan metode dan sikap ilmiah dalam menyelesaikan permasalahan (Sambada, 2012).

Kemampuan berpikir kreatif didefinisikan sebagai kemampuan yang memungkinkan siswa menghasilkan solusi atau ide yang baru dan tepatguna dari berbagai sudut pandang berdasarkan data atau informasi yang ada (Rizal et al., 2020). Potensi siswa dalam berpikir kreatif dapat dikembangkan melalui suatu pembelajaran yang berorientasi pada permasalahan sehingga siswa dapat mengidentifikasi permasalahan dan menyusun solusi yang beragam (Nuha, et al., 2018). Terdapat 4 indikator kemampuan berpikir kreatif yaitu (1) Fluency, adalah kemampuan siswa dalam menghasilkan solusi yang relevan dengan permasalahan (2) Flexibility, adalah kemampuan siswa menghasilkan suatu solusi yang beragam dari suatu permasalahan (3) Originality, adalah kemampuan siswa menghasilkan ide yang baru dari suatu permasalahan (4) Elaboration, adalah kemampuan siswa melengkapi ide yang telah disampaikan (Torrance, 1979). 
Kemampuan problem solving merupakan suatu kemampuan dalam menganalisa permasalahan, menghasilkan solusi, hingga melakukan evalausi terhadap solusi yang didapatkan (Anugraheni, 2019). Penyelesaian masalah dengan menerapkan proses sains akan mempermudah siswa menyusun solusi berdasarkan pengetahuan yang dimilikinya (Sambada, 2012). Terdapat 5 indikator pada kemampuan problem solving yaitu: (1) Usefull description, adalah kemampuan mendeskripsikan solusi dari suatu permasalahan (2) Physics appproach, adalah kemampuan menghasilkan solusi berdasarkan penerapan konsep konsep fisika (3) Spesific application of physics, adalah kemampuan menghasilkan solusi berdasarkan penerapan konsep fisika yang spesifik (5) Logical progression adalah kemampuan menghasilkan solusi yang logis (Docktor et al., 2016).

Pendekatan STEAM merupakan suatu pendekatan yang memadukan aspek science, technology, engineering, arts, dan mathematics menjadi satu kesatuan. Pendekatan STEAM akan menjadi sarana dalam membentuk karakter dan pola pikir siswa yang lebih kreatif karena pembelajaran dilakukan berdasarkan 5 bidang ilmu yang dipadukan (Henriksen, 2014). Dengan keterpaduan 5 bidang ilmu ini, siswa akan lebih mudah menyelesaikan permasalahan yang diberikan secara lebih kreatif dan inovatif (Nurhikmayati, 2019). Pelibatan peran siswa secara langsung dalam pembelajaran akan meninggalkan kesan yang mendalam bagi memori siswa sehingga pembelajaran yang diperoleh akan lebih membekas dan lebih mudah diaplikasikan dalam kehidupan sehari-hari (Conner et al., 2017).

Kemampuan berpikir kreatif dan problem solving dapat dinilai melalui suatu instrumen penilaian. Pemilihan materi yang tepat menjadi salah satu hal yang harus dipertimbnagkan secara matang agar penilaian yang dilakukan mendapatkan hasil yang maksimal. IPA khususnya materi pada bidang fisika dirasa cocok sebagai dasar pengembangan assesmen. Materi pada bidang fisika pada umumnya berdasarkan pada penelitian dan percobaan sehingga siswa akan terbiasa dalam menghasilkan ide baru dari suatu permasalahan yang sedang dihadapinya (Wahyuni et al., 2019). Topik bahasan getaran dan gelombang dirasa cocok dalam pengembangan kemampuan berpikir kreatif dan problem solving pada siswa. Topik bahasan getaran dan gelombang adalah suatu topik yang dekat dengan kehidupan siswa, seperti getaran pada tali, gelombang bunyi, hingga teknologi USG, sehingga siswa akan lebih mudah dalam mengaplikasikan pengetahuan yang dimilikinya dalam menghadapi permasalahan yang ada (Yulianti dan Zhafirah, 2020).

Assesmen kemampuan berpikir kreatif berpendekatan STEM sebelumnya pernah dikembangkan dengan kategori sangat baik dengan nilai rata-rata sebesar 4,07 (Chasanah et al., 2017). Assesmen kemampuan problem solving berpendekatan STEM pernah dikembangkan sebelumnya pada kriteria siswa ahli dengan dengan rata-rata kemampuan siswa sebesar 79\% (Ringo et al., 2019). Assesmen yang dikembangkan sebelumnya belum diintegrasikan dengan aspek arts, hanya memadukan 4 bidang ilmu. Selain itu assesmen yang ada terbatas pada pengukuran salah satu kemampuan saja tanpa adanya integrasi aspek arts pada pendekatan yang digunakan, sehingga perlu adanya keterbaruan pengembangan instrumen penilaian untuk mengukur kemampuan berpikir kreatif dan problem solving berpendekatan STEAM yang dilakukan terpisah dengan proses pembelajaran.

\section{Metode}

Jenis penelitian yang digunakan adalah penelitian dan pengembangan. Model yang digunakan adalah 4-D terdiri dari tahap define, design, develop, and disseminate. Hsil akhir 
dari penelitian ini menghasilkan suatu assesmen kemampuan berpikir kreatif dan problem solving berpendekatan STEAM. Penelitian ini terbatas pada tahap develop karena adanya keterbatasan waktu dan biaya. Tahap define dilakukan analisis pendahuluan melalui studi literatur, analisis siswa berdasarkan KD dan kedalaman materi yang dipelajari siswa, serta merumuskan tujuan pembelajaran yang dikembangkan berdasarkan pilihan KD yang telah ditetapkan sebelumnya. Tahap design terdiri dari proses perencanaan produk berupa penyusunan kisi-kisi soal, tabel indikator, soal dan pembahasan, hingga lembar validasi. Tahap develop dilakukan proses penelaah oleh ahli dan serangkaian revisi.

Tahapan selanjutnya adalah proses validasi oleh ahli materi serta uji keterbacaan oleh guru selaku pengguna. Setelah tahapan validasi dan uji keterbacaan, produk kemudian dilakukan revisi berdasarkan masukan yang diberikan oleh validator ahli materi maupun guru sebagai pengguna. Setelah produk dinyatakan layak, dilakukan uji empiris guna menentukan tingkat validitas dan reliabilitas butir soal.

\section{Hasil dan Pembahasan \\ 3.1. Deskripsi Hasil Pengembangan}

Penelitian dan pengembangan yang dilakukan menghasilkan produk berupa assesmen penilaian pada materi getaran dan gelombang. Materi getaran dan gelombang merupakan materi yang diajarkan pada kelas VIII SMP semester 2. Assesmen penilaian yang dikembangkan adalah soal uraian yang dilengkapi dengan pembahasan, skoring, petunjuk penilaian, tabel indikator kemampuan berpikir kreatif, tabel indikator problem solving, tabel aspek STEAM, dan kisi-kisi soal. Produk ini kemudian disajikan dalam bentuk buku berukuran B5. Butir soal yang dikembangkan berjumlah 62 soal uraian, dengan rincian 27 butir soal kemampuan berpikir kreatif dan 35 butir soal problem solving. Assesmen yang dikembangkan terdiri dari 6 bahasan pada materi getaran dan gelombang dengan integrasi aspek STEAM.

\subsection{Hasil Validasi dan Uji Keterbacaan}

Validasi dilakukan oleh dua orang dosen yang menguasai topik bahasan getaran dan gelombang untuk menentukan kelayakan materi dan konstruk produk. Hasil dari validasi materi menunjukkan bahwa produk berada pada kategori sangat layak dengan nilai rata-rata sebesar 94,6\%. Hasil validasi konstruk menunjukkan bahwa produk berada pada kategori sangat layak dengan nilai rata-rata sebesar 94,3 . Nilai validasi materi dan konstruk jika dirata-rata berada pada kategori sangat layak dengan nilai rata-rata sebesar 94,4\%. Berdasarkan nilai validasi ini menyatakan bahwa assesmen yang dikembangkan berada pada kategori sangat layak. Masukan serta komentar yang disampaikan oleh validator maupun guru dijadikan acuan dalam perbaikan sehingga didapatkan produk yang lebih baik.

Produk yang dihasilkan kemudian diuji keterbacaan kepada guru sebagai pengguna. Guru sebagai subjek penelitian merupakan guru IPA SMPN 1 Tumpang berjumlah 2 orang. Hasil uji keterbacaan menunjukkan bahwa assesmen yang dikembangkan berada pada kategori sangat layak dengan nilai rata-rata sebesar 99,4\%. Masukan dan komentar yang diberikan dari hasil uji keterbacaan ini kemudian dijadikan dasar perbaikan produk. 


\subsection{Hasil Uji Empiris}

Uji validitas dan reliabilitas butir soal merupakan uji yang akan dilakukan pada tahap ini. Siswa SMP kelas IX dengan jumlah total 35 siswa yang berasal dari gabungan siswa MPN 1 Tumpang dan SMPN 3 Malang akan menjadi subjek penelitian. Uji empiris ini menggunakan bantuan aplikasi IBM SPSS Statistic 25 dengan nilai taraf signifikansi sebesar 0,05. Saat nilai $r_{\text {hitung }}>r_{\text {tabel }}$ maka soal dikatakan valid (Ary, et al., 2010). Butir soal dikatakan reliabel saat nilai yang didapat lebih dari 0,400 (Guspatni and Kurniawati, 2018). Adapun kriteria nilai hasil uji reliabilitas adalah sebagai berikut.

Tabel 1. Kriteria hasil uji reliabilitas

\begin{tabular}{|l|l|}
\hline Nilai Korelasi & Kriteria \\
\hline $0,800-1,000$ & Sangat Tinggi \\
$0,600-0,799$ & Tinggi \\
$0,400-0,599$ & Cukup Tinggi \\
$0,200-0,399$ & Rendah \\
$0,000-0,199$ & Sangat Rendah \\
\hline
\end{tabular}

Berdasarkan analisis hasil uji empiris, maka didapatkan hasil yang diperinci sebagai berikut.

\subsubsection{Uji Validitas}

Uji validitas dilakukan pada masing-masing butir soal di setiap setiap kemampuan. Hasil uji validitas butir soal kemampuan berpikir kreatif diilustrasikan pada Gambar 1 berikut.

\section{Gambar 1. Hasil Uji Validitas Butir Soal Kemampuan Berpikir Kreatif}

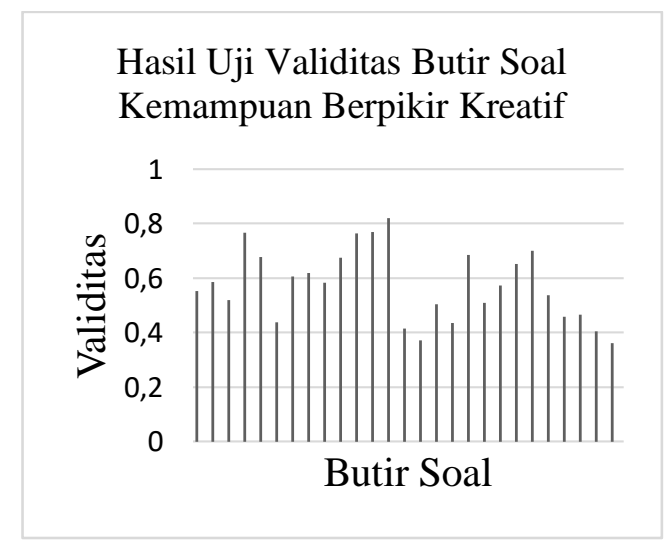

Hasil uji validitas butir soal kemampuan problem solving diilustrasikan pada Gambar 2 berikut. 


\section{Gambar 2. Hasil Uji Validitas Butir Soal Kemampuan Problem Solving}

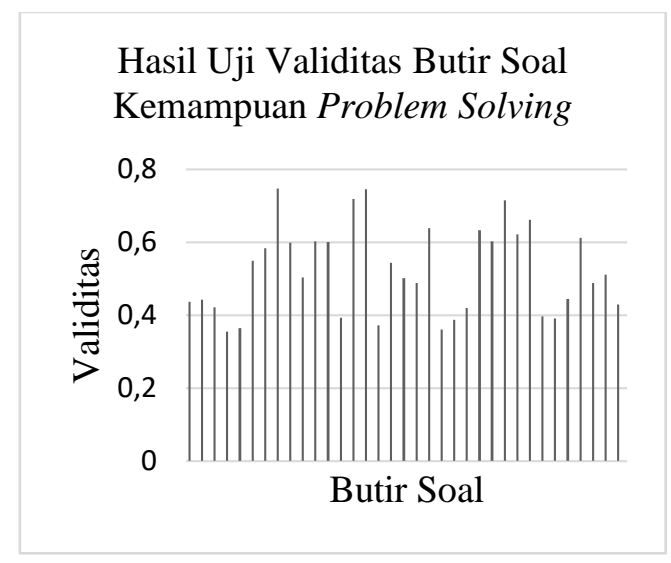

Besaran nilai $\mathrm{r}_{\text {hitung }}$ dengan 35 responden adalah 0,325. Berdasarkan diagram batang pada Gambar 1 dan Gambar 2 diatas, dapat dilihat bahwa tidak terdapat butir soal dengan $r_{\text {hitung }}$ kurang dari 0,325 . Hal ini menyatakan bahwa semua butir soal dikategorikan valid.

\subsubsection{Uji Reliabilitas}

Hasil uji reliabilitas butir soal kemampuan berpikir kreatif mendapatkan nilai sebesar 0,922 serta butir soal dengan kemampuan problem solving mendapatkan nilai sebesar 0,920 . Berdasarkan kriteria nilai pada Tabel 1, kedua nilai ini dikategorikan dengan kriteria sangat reliabel, sehingga keseluruhan butir soal dikategorikan reliabel.

\section{Simpulan}

\subsection{Kesimpulan}

Assesmen kemampuan berpikir kreatif dan problem solving berpendekatan STEAM dikategorikan sangat layak, valid dan reliabel.

\subsection{Saran}

Adapun saran dari penelitian dan pengembangan ini adalah sebagai berikut. (1) Perlu adanya pengembangan assesmen serupa pada materi yang berbeda (2) Perlu adanya pengembangan assesmen serupa pada kemampuan siswa lainnya, (3) Perlu adanya pengembangan assesmen serupa dengan menggunakan pendekatan yang lebih lengkap sesuai dengan perkembangan penelitian yang ada (4) Perlu diimplementasikan pada penelitian eksperimen agar dapat digunakan untuk menilai kemampuan berpikir kreatif dan problem solving siswa melalui pembelajaran berpendekatan STEAM.

\section{Daftar Rujukan}

Anugraheni, I. (2019). Pengaruh Pembelajaran Problem Solving Model Polya Terhadap Kemampuan Memecahkan Masalah Matematika Mahasiswa. Jurnal Pendidikan (Teori Dan Praktik), 4(1), 1.

Ary, D., Jacobs, L. C., \& Razavieh, A. (2010). Introduction to research in education 8th edition, Wardswoth Cengage Learning. Canada: Nelson Education Ltd Exotic Classic.

Chasanah, L., Kaniawati, I., \& Hernani, H. (2017, September). How to Assess Creative Thinking Skill in Making Products of Liquid Pressure?. In Journal of Physics: Conference Series (Vol. 895, No. 1, p. 012164). IOP Publishing. 
Conner, L. D. C., Tzou, C., Tsurusaki, B. K., Guthrie, M., Pompea, S., \& Teal-Sullivan, P. (2017). Designing STEAM for broad participation in science. Creative Education, 8(14), 2222.

Docktor, J. L., Dornfeld, J., Frodermann, E., Heller, K., Hsu, L., Jackson, K. A., ... \& Yang, J. (2016). Assessing student written problem solutions: A problem-solving rubric with application to introductory physics. Physical review physics education research, 12(1), 010130.

Guspatni, G., \& Kurniawati, Y. (2018, April). Validity and Reliability Testing of an e-learning Questionnaire for Chemistry Instruction. In IOP Conference Series: Materials Science and Engineering (Vol. 335, No. 1, p. 012102). IOP Publishing.

Henriksen, D. (2014). Full STEAM ahead: Creativity in excellent STEM teaching practices. The STEAM journal, 1(2), 15.

Mulhayatiah, D., Kindi, A., \& Dirgantara, Y. (2019, February). Moodle-blended problem solving on student skills in learning optical devices. In Journal of Physics: Conference Series (Vol. 1155, No. 1, p. 012073). IOP Publishing.

Nuha, M. A., Waluya, S. B., \& Junaedi, I. (2018). Mathematical Creative Process Wallas Model in Students Problem Posing with Lesson Study Approach. International Journal of Instruction, 11(2), 527-538.

Nurhikmayati, I. (2019). Implementasi STEAM Dalam Pembelajaran Matematika. Didactical Mathematics, 1(2).

Rahayu, I. A. T., \& Adistana, G. A. Y. P. (2018). Mengembangkan Keterampilan Memecahkan Masalah Melalui Pembelajaran Berdasar Masalah. JP (Jurnal Pendidikan): Teori dan Praktik, 3(2), 86-91.

Ringo, E. S., Kusairi, S., Latifah, E., \& Tumanggor, A. M. (2019, December). Student's Problem Solving Skills in Collaborative Inquiry Learning Supplemented by Formative E-Assessment: Case of Static Fluids. In Journal of Physics: Conference Series (Vol. 1397, No. 1, p. 012012). IOP Publishing.

Ary, D., Jacobs, L. C., \& Razavieh, A. (2010). Introduction to research in education 8th edition, Wardswoth Cengage Learning. Canada: Nelson Education Ltd Exotic Classic.

Chasanah, L., Kaniawati, I., \& Hernani, H. (2017, September). How to Assess Creative Thinking Skill in Making Products of Liquid Pressure?. In Journal of Physics: Conference Series (Vol. 895, No. 1, p. 012164). IOP Publishing.

Conner, L. D. C., Tzou, C., Tsurusaki, B. K., Guthrie, M., Pompea, S., \& Teal-Sullivan, P. (2017). Designing STEAM for broad participation in science. Creative Education, 8(14), 2222.

Docktor, J. L., Dornfeld, J., Frodermann, E., Heller, K., Hsu, L., Jackson, K. A., ... \& Yang, J. (2016). Assessing student written problem solutions: A problem-solving rubric with application to introductory physics. Physical review physics education research, 12(1), 010130.

Guspatni, G., \& Kurniawati, Y. (2018, April). Validity and Reliability Testing of an e-learning Questionnaire for Chemistry Instruction. In IOP Conference Series: Materials Science and Engineering (Vol. 335, No. 1, p. 012102). IOP Publishing.

Henriksen, D. (2014). Full STEAM ahead: Creativity in excellent STEM teaching practices. The STEAM journal, 1(2), 15.

Mulhayatiah, D., Kindi, A., \& Dirgantara, Y. (2019, February). Moodle-blended problem solving on student skills in learning optical devices. In Journal of Physics: Conference Series (Vol. 1155, No. 1, p. 012073). IOP Publishing.

Nuha, M. A., Waluya, S. B., \& Junaedi, I. (2018). Mathematical Creative Process Wallas Model in Students Problem Posing with Lesson Study Approach. International Journal of Instruction, 11(2), 527-538.

Rahayu, I. A. T., \& Adistana, G. A. Y. P. (2018). Mengembangkan Keterampilan Memecahkan Masalah Melalui Pembelajaran Berdasar Masalah. JP (Jurnal Pendidikan): Teori dan Praktik, 3(2), 86-91.

Ringo, E. S., Kusairi, S., Latifah, E., \& Tumanggor, A. M. (2019, December). Student's Problem Solving Skills in Collaborative Inquiry Learning Supplemented by Formative E-Assessment: Case of Static Fluids. In Journal of Physics: Conference Series (Vol. 1397, No. 1, p. 012012). IOP Publishing.

Rizal, R., Rusdiana, D., Setiawan, W., \& Siahaan, P. (2020, April). Creative thinking skills of prospective physics teacher. In Journal of Physics: Conference Series (Vol. 1521, No. 2, p. 022012). IOP Publishing.

Sambada, D. (2012). Peranan kreativitas siswa terhadap kemampuan memecahkan masalah fisika dalam pembelajaran kontekstual. Jurnal Penelitian Fisika dan Aplikasinya (JPFA), 2(2), 37-47. 
Torrance, E. P. (1974). Norm-Technical Manual Torrance Test of Creative Thinking, Verbal test, form A and B. Figural test, form A and B. Lexing ton, Massachusetts: Personal Press Inc.

Wahyuni, S., \& Husein, S. (2019, June). Physics learning devices based on guided inquiry with experiment to improve students' creativity. In Journal of Physics: Conference Series (Vol. 1233, No. 1, p. 012034). IOP Publishing.

Yulianti, E., \& Zhafirah, N. (2020). Peningkatan Kemampuan Penalaran Ilmiah Siswa Sekolah Menengah Pertama Melalui Model Pembelajaran Inkuiri Terbimbing. Jurnal Penelitian Pendidikan IPA, 6(1), 125130. 